\title{
The development of calorimetry and thermochemistry in Portugal
}

\author{
Manuel A. V. Ribeiro da Silva
}

Received: 16 March 2010/ Accepted: 16 March 2010/Published online: 30 March 2010

(C) Akadémiai Kiadó, Budapest, Hungary 2010

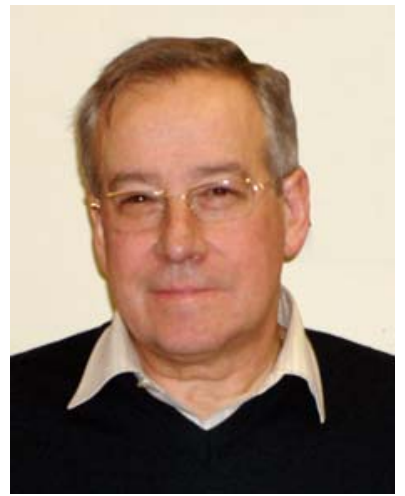

Guest Editor

Calorimetry is the art of measuring the heat effects involved in chemical, physical or biological processes. The devices used for the quantitative determination of the heat effects are the so-called calorimeters. The origins of Calorimetry date back to the eighteenth century, almost 200 years later than the modern principles of thermometry were established by Galileu Galilei (1564-1642). After the work and attempts of different scientists to define and establish a heat unit, it was the Swedish researcher M. Wilke who attempted to establish the measurement methods and to determine a heat unit in 1772 . Soon after, in 13th June 1780, in a meeting at the French Academy, A. L. Lavoisier and P. S. Laplace, on their lecture Memoire sur la chaleur, presented the first ice calorimeter. They were the first scientists to call the device for measuring heat

M. A. V. Ribeiro da Silva ( $\square)$

Centro de Investigação em Química, Faculty of Science,

University of Porto, Porto, Portugal

e-mail: risilva@fc.up.pt a calorimeter. These scientists used the original calorimeter and modified versions of it, to measure heats of combustion, heats of respiration, and specific heats. These are the first reported works on the energy changes of chemical reactions and so the period of 1780-1840, in which Lavoisier, Laplace, and Hess made the first measurements of heats of reaction, is considered the beginning of Thermochemistry, being calorimetry the oldest experimental technique for investigating the thermodynamics of chemical reactions.

By 1840 , Hess has established his Law, that the heat exchanged (evolved or absorbed) depends only of the initial and final states of the reaction being independent of the number of intermediate steps, which could either be postulated or observed. This Law is the basis of Thermochemistry and is in accord with the First Law of Thermodynamics, which was first formulated by Helmholtz only in 1847.

In the later half of the nineteenth century, extensive studies on thermochemistry were made by Thomsen (18511885) in Copenhagen and by Berthelot (1881-1905), at the Collège de France, in Paris, who were motivated by the mistaken idea that the driving force of a chemical reaction lay in the heat of reaction. With the realization, near the turn of the nineteenth century, that entropy changes must also to be considered as a component of the driving force of reaction, the impetus of this work declined and the classical period of thermochemistry ended.

Notwithstanding the great improvement verified in the period of 1900-1930 on the design and development of combustion bombs with the prominent work of some distinguished scientists like Dickinson who published his classic paper on the procedures, apparatus, and calculations in combustion calorimetry, and the work of T. W. Richards and collaborators for the significant development and 
refinement in the techniques of adiabatic calorimetry, the impetus was not regained until the late 1920s when it was realized that the further development of chemical technology depended on the existence of a reliable body of physicochemical data.

Modern thermochemistry can be regarded as started in 1930 with the work of Rossini at the National Bureau of Standards, now called National Institute of Standards and Technology, Washington, D.C., with the accurate measurements of the standard enthalpy of formation of water. This work set quite new standards of precision and accuracy and was followed at the Bureau by measurements of the energy of combustion of benzoic acid, the standard substance for calibration of combustion calorimeters and the enthalpy of formation of carbon dioxide. On the 1930s, the requirements of the petroleum industry for establishing precise thermochemical properties of hydrocarbons and related compounds lead to a considerable expansion and interest in thermochemistry, which has continued since that time.

Nowadays, thermochemical data are essential for the understanding of chemical problems, such as energetics of chemical bonds, structural properties and reactivity, and even more applied fields like industrial chemistry, biochemistry, medical and life sciences, environmental chemistry, space fuels, and military matters, etc.

The second half of the twentieth century was a period of great development of research thermochemical laboratories worldwide, in countries like the USA, Soviet Union, Great
Britain, Sweden, Germany, France, Poland, Italy, Netherlands, Japan, and China, although a large number of these outstanding laboratories are not active anymore.

The Portuguese University policy of the late $60 \mathrm{~s}$ invested on the development of scientific research and for that sent abroad, to outstanding research units mainly in UK, USA, and Germany, a considerable number of young scientists to get their scientific training in areas not at that time established in Portugal. Under this scheme, in what concerns thermochemistry research, some of the young lectures of Portuguese Universities were sent to be trained and acquainted with the research that was being done in the top laboratories of UK, like Manchester University (Prof. H. A. Skinner and Dr. G. Pilcher), University of Surrey (Prof. R. J. Irving), and University of Lund, Sweden (Prof. I. Wadsö). On their return to Portugal, those recent trained researchers started new lines of research in the Universities of Porto and of Lisbon which, nowadays, together with the scientific research on related area done in the University of Coimbra, put Portugal on the worldwide frontline of this kind of research.

This issue of Journal of Thermal Analysis and Calorimetry collects some invited papers on current research on the subject that constitutes a small sample of the work in molecular energetics that is done in Portugal. I take the opportunity to thank the authors of the papers and the reviewers for their work in helping to prepare the present collection of these scientific papers. 